\title{
ABSORÇÃO E INFILTRAÇÃO DE ÁGUA POR RAÍZES DE BATATA- DOCE, ATRAVÉS DE FERIMENTOS DURANTE A LAVAGEM
}

\author{
Adonai Gimenez Calbo*; Amauri Alves Nery \\ Embrapa Hortaliças, C.P. 218 - CEP: 70359-970 - Brasília, DF. \\ *Autor correspondente <adonai@cnph.embrapa.br>
}

\begin{abstract}
RESUMO: Raízes intactas e segmentos transversais de batata-doce (Ipomea batatas L. Lam) foram totalmente ou parcialmente imersos em água. Raízes ou segmentos parcialmente imersos ficaram com menos de $10 \%$ da superfície externa fora da água, em um suspiro. Nestes ensaios a pressão da atmosfera interna das raízes parcialmente imersas manteve-se apenas alguns milímetros inferior a pressão atmosférica. Nas raízes totalmente imersas a pressão reduziu-se quase linearmente até mais de $1 \mathrm{~m}$ de coluna de água e depois voltou a aumentar lentamente. Nas raízes intactas ou nos seus segmentos transversais totalmente imersos, houve maior infiltração de água nos volumes intercelulares do que nas raízes ou segmentos parcialmente imersos. Nas raízes intactas praticamente houve apenas absorção de água através das paredes e membranas celulares. Nos segmentos a infiltração de água através dos volumes intercelulares foi dominante. Considerando-se as dimensões transversais dos volumes intercelulares, sugere-se que partículas como bactérias e esporos possam ser arrastados para o interior órgão pela infiltração de água durante a lavação dos tecidos mecânicamente danificados.
\end{abstract}

Palavras-chave: Ipomea batatas, volume intercelular, sanitização, lavação, hortaliça

\section{WATER ABSORPTION AND INFILTRATION IN SWEET-POTATO WOUND ROOTS DURING WASHING}

\begin{abstract}
Intact roots and transversal root segments of sweet-potato (Ipomea batatas L. Lam) were partially or completely submerged in water. In partially submerged roots less than $10 \%$ of the dermal surface remained exposed to air through a vent. Internal atmosphere pressure in partially submerged roots remained a few millimeters bellow the atmospheric pressure, while a much larger and nearly linear pressure reduction occurred in completely submerged roots. This linear phase caused a pressure reduction larger than $1 \mathrm{~m}$ of water column. After that, the pressure started to rise slowly. The observed pressure reduction was smaller than the one observed in the constant pressure manometry procedure where the roots were sealed with epoxy resin, which precluded any water infiltration and changes of root volume. Partially submerged intact roots and segments were less subject to intercellular water infiltration than the completely submerged ones. The mass increase of submerged intact roots was caused mainly by water absorption, a process which is known to exclude molecules with a size larger than a few nanometers. In transversely segmented roots most water entered by intercellular volume infiltration, which may introduce fungi spores and bacteria and other particles inside the damaged organ. Key words: Ipomea batatas, intercellular volume, sanitation, water absorption, vegetable
\end{abstract}

\section{INTRODUÇÃO}

A limpeza ou a lavagem de uma hortaliça por imersão em água pura ou em solução aquosa (vinagre ou hipoclorito de sódio) constuma ser uma prática no processo de comercialização e de consumo. Tal prática, além de melhorar a aparência visual do produto, retira as partículas de solo ou de outras impurezas da superfície da hortaliça.

A imersão da hortaliça em água ou em solução aquosa pode em tese, provocar, a obstrução das trocas gasosas mediante o envolvimento da superfície do órgão por uma fina camada de água. Adicionalmente, seja por adsorção de água as paredes que faceiam os volumes intercelulares, seja pela redução de pressão previamente descrita em órgãos selados (Nery \& Calbo, 1994) a lavação pode provocar a entrada de impurezas, como microorganismos em camadas internas do órgão.
A lavação, talvez, por ser um procedimento trivial praticado mundialmente pelos comerciantes e consumidores, tem sido pouco estudada. Neste trabalho, procurou-se demonstrar algumas conseqüências biofísicas e fisiológicas advindas do processo de lavação das hortaliças.

\section{MATERIAL E MÉTODOS}

\section{Material vegetal}

Para os estudos de lavação, utilizaram-se raízes intactas e segmentos radiculares da batata-doce (Ipomea batatas L. Lam cv. Brazlândia Roxa). De cada raiz foram aproveitados dois segmentos longitudinais com cerca de $0,1 \mathrm{~kg}$. Para tirar estes dois segmentos as raízes foram cortadas em quatro pedaços longitudinais dos quais os dois segmentos quase cilíndricos do centro foram 
aproveitados. Nos ensaios a raízes foram sempre imersas em frascos de água em temperatura ambiente, de tal forma que se assumiu a existência de equilíbrio térmico. A lâmina de água empregados foram suficientes para cobrir as raízes sem causar pressão substancial, o que aumentaria a infiltração de água.

\section{Variação do Volume Gasoso}

A variação do volume gasoso intercelular $\left(\Delta \mathrm{V}_{\mathrm{g}}\right)$ nas raízes de batata-doce durante a imersão em água foi estimada com a Equação 1 (Calbo \& Nery, 1995):

$$
\mathrm{V}_{\mathrm{gf}}-\mathrm{V}_{\mathrm{gi}}=\Delta \mathrm{V}_{\mathrm{g}}=\Delta \mathrm{V}_{\mathrm{p}}-\Delta \mathrm{M}_{\mathrm{p}} \cdot \mathrm{V}_{\mathrm{ew}}
$$

onde $V_{g f}$ é o volume gasoso final do órgão, $V_{g i}$ é o volume gasoso inicial do órgão, $\Delta \mathrm{V}_{\mathrm{g}}$ é a variação do volume gasoso do órgão, $\Delta \mathrm{V}_{\mathrm{p}}$ é a variação do volume do produto, $\Delta \mathrm{M}_{\mathrm{p}}$ é a variação da massa do produto durante o ensaio e $v_{\text {ew }}$ é o volume especifico da água na temperatura do ensaio.

\section{Variação do volume intercelular}

Os volumes intercelulares são formados entre vértices de três ou mais células vizinhas (Jeffree et al., 1986; Koloffel \& Linssen, 1985) e originam uma malha por onde ocorrem as trocas gasosas de $\mathrm{O}_{2}, \mathrm{CO}_{2}$ e outros gases. Sob o crescimento do órgão causado pela entrada de água nos tecidos o volume desta malha de volumes intercelulares também aumenta. Se o aumento do volume do produto $\left(\Delta \mathrm{V}_{0}\right)$ ocorrer sem rupturas nas lamelas médias então o aumento do volume intercelular $V_{\text {d }}$ deve ser proporcional ao aumento do volume do órgão (Equação 2).

$$
\Delta \mathrm{V}_{\mathrm{i}}=\Delta \mathrm{V}_{\mathrm{p}} \cdot \mathrm{V}_{\mathrm{io}} / \mathrm{V}_{\mathrm{oi}}
$$

onde $\mathrm{V}_{\mathrm{oi}}$ é o volume inicial do produto e $\mathrm{V}_{\mathrm{io}}$ é o volume intercelular inicial. $O \mathrm{~V}_{\mathrm{oi}}$ foi obtido por meio da imersão do órgão em água utilizando-se do Princípio de Arquimedes. $V_{i 0}$ foi obtido pela diferença entre o volume gasoso inicial e 0 volume gasoso nulo de raízes infiltradas com água empregando-se a Equação 1.

Ensaio 1 - Acompanhamento da Pressão Interna do Órgão: Para esse ensaio, acoplou-se a cada um dos dois segmentos intermediários de uma mesma raiz de batata-doce um manômetro de coluna de água para trabalhar a volume constante, sendo que em um dos segmentos, também, foi acoplado, com o uso de selante plástico, uma câmara de Devaux modificada, contendo um tubo de plástico (suspiro) de cerca de $100 \mathrm{~mm}$ de comprimento e $5 \mathrm{~mm}$ de diâmetro interno para servir de ligação entre a atmosfera interna do órgão e o meio ambiente. $\mathrm{O}$ acoplamento do manômetro à atmosfera interna do órgão foi efetuado fixando à superfície do órgão uma câmara externa com volume morto próximo a zero com um capilar de cerca de 1 metro de comprimento e diâmetro de 0,2 mm inserido em seu centro (Figura 1). Para o trabalho com menisco em posição constante, o braço do manômetro oposto ao órgão tinha sua altura ajustada de maneira a manter constante o nível da água no braço próximo das raízes, cujo volume gasoso total é da ordem de uma dezena de mililitros de atmosfera interna (§6\% v/v). Em seguida, acompanhou-se a pressão interna dos órgãos imersos em água por cerca de 50 minutos. Depois disto, retiraram-se os segmentos da água e continuou-se a acompanhar a sua pressão interna até ela voltar a se aproximar da pressão atmosférica local.

Ensaio 2 - Taxa de Difusão de Oxigênio: Acoplou-se à superfície, previamente escarificada, dos segmentos de batata-doce (cv. Brazlândia Roxa), uma placa de acrílico circular de diâmetro $(30 \mathrm{~mm})$ com um eletrodo de platina nivelado e centralizado para medição da taxa de difusão de oxigênio (TDO), avaliada de acordo com a corrente elétrica que fluiu do eletrodo de referência $\left(\mathrm{Ag}^{+} / \mathrm{Ag}\right)$ inserido lateralmente na raiz para o eletrodo de platina onde ocorre a redução do $\mathrm{O}_{2}$, sob uma diferença de potencial de $650 \mathrm{mV}$, conforme a metologia descrita por Calbo et al (1995). O ensaio de lavagem iniciou-se depois de um período inicial de equilíbrio de 10minutos.

Ensaio 3 - Absorção e Infiltração de Água: Num ensaio com 10 repetições a massa e o volume dos dois segmentos intermediários de uma mesma raiz da batatadoce foram inicialmente medidos por pesagem e estimado de acordo com medição do empuxo da raiz imersa em água (princípio de Arquimedes) com uma balança com precisão de 0,01g. Nos segmentos do controle foi acoplado um suspiro, descrito no primeiro ensaio. Em seguida os dois segmentos de um mesmo órgão foram imersos em um recipiente com água por 50 min., tomando-se o cuidado de não imergir na água o tubo plástico do controle. Após o ensaio, a massa e o volume dos segmentos radiculares, secos com papel toalha, foram novamente medidos.

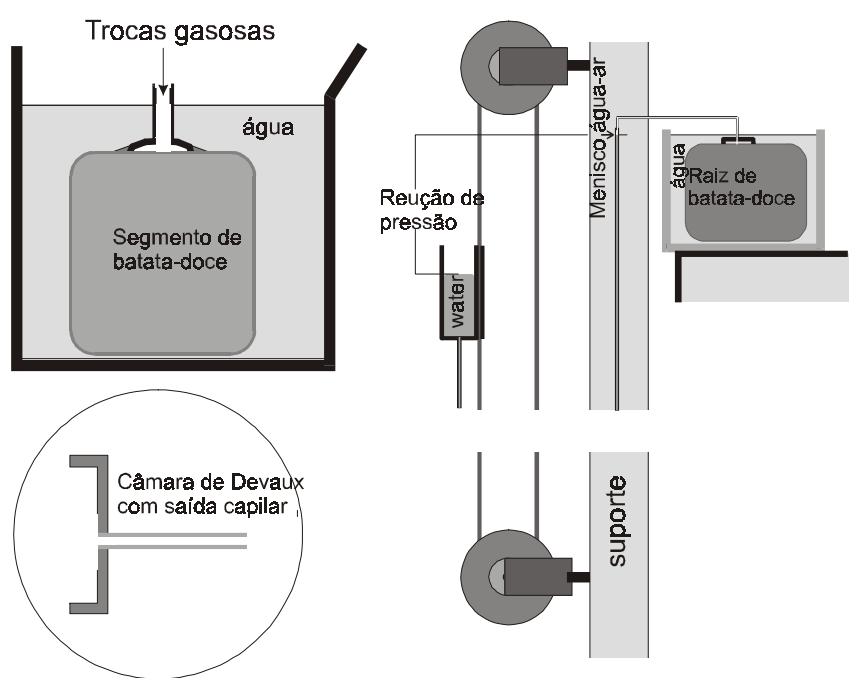

Figura 1- Suspiro para assegurar equilíbrio de pressão entre as atmosferas interna e externa durante a imersão de segmentos de raízes de batata-doce. Esquema de uma câmara de Devaux com conexão para ligar a um manômetro de coluna de água conforme descrito em Nery \& Calbo (1994). 
Ensaio 4 - Raízes Intactas e Segmentadas: Raízes batata-doce cv. Brazlândia Roxa intactas e cortadas ao meio de foram imersas total e parcialmente em água. Este ensaio de imersão por uma hora teve dez repetições. A lâmina de água sobre as raízes acomodadas horizontalmente foi inferior a $4 \mathrm{~cm}$. Nas raízes denominadas parcialmente imersas se acoplou um suspiro (Figura 1) com massa de calafetar plástica. A massa e volume das raízes foi medida no início e após a imersão. Depois disto, as raízes foram segmentada transversalmente, imersas em água, e submetidas a vácuo por dois minutos para remover os gases da atmosfera interna, que borbulharam para fora do órgão. Desligou-se a bomba de vácuo e abriu-se a entrada de ar. A pressão sobre a água voltou ao valor inicial. Nos volumes intercelulares o baixo número de moléculas gasosas remanescentes não pôde conter a água que foi pressionada para o interior do órgão. Após 15 minutos as raízes foram removidas do banho. Os volumes intercelulares estavam agora totalmente infiltrados com água (Calbo \& Nery, 1995).

Em seguida a aplicação do método diferencial (Equação 1) calculou-se o volume volume gasoso inicial de cada raiz. Com a Equação 2 estimou-se a variação do volume intercelular. A quantidade de água infiltrada foi calculada presumindo-se que a quantidade de água absorvida foi igual aquela das raízes intactas e parcialmente imersas. Finalmente a quantidade de água absorvida pelas células a partir dos volumes intercelulares foi calculada subtraindo-se da quantidade de água infiltrada a quantidade de água contida nos volumes intercelulares ao término do ensaio $\left(\Delta \mathrm{V}_{\mathrm{g}}-\Delta \mathrm{V}_{\mathrm{i}}\right)$.

\section{RESULTADOS E DISCUSSÕES}

\section{Redução de Pressão Interna}

No primeiro ensaio, a pressão interna dos segmentos radiculares de batata-doce com suspiro manteve-se ligeiramente inferior a pressão atmosférica. Diferentemente, a pressão interna dos segmentos de batata-doce completamente imersos reduziu de maneira quase linear, durante $50 \mathrm{~min}$., atingindo valores superiores a 1,0 metro de coluna d'água (Figura 2). Após a retirada

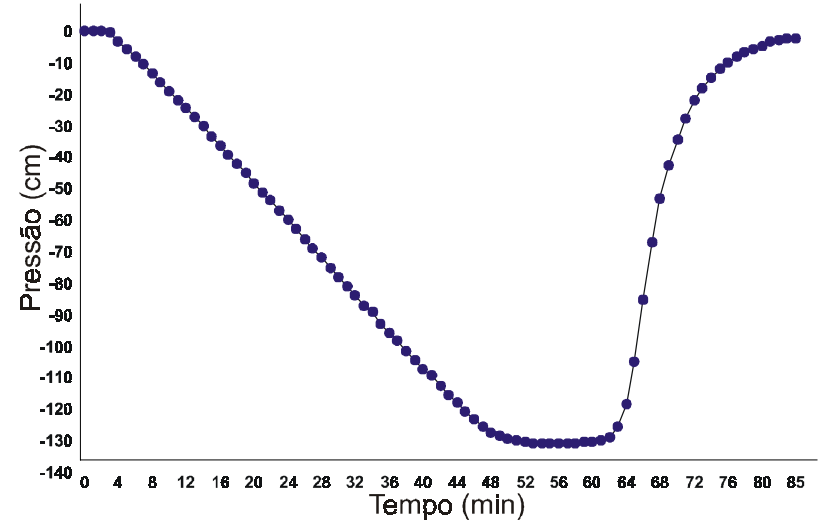

Figura 2 - Variação da pressão interna dos segmentos radiculares de batata-doce em função do tempo de imersão em água. dos segmentos radiculares completamente imersos em água, a pressão interna continuou a diminuir por cerca de $5 \mathrm{~min}$. Após esse período, a superfície externa secou e a pressão interna do órgão aumentou até retornar a pressão barométrica local, cerca de $30 \mathrm{~min}$. depois dos segmentos terem sido colocados sobre a bancada.

As curvas de pressão interna versus tempo de imersão (Figura 2) foram similares às obtidas por manometria de volume constante (Figura 3 ), na qual a raiz é envolvida por resina epoxi para manter constante 0 volume da atmosfera interna do órgão (Nery \& Calbo, 1994). A redução da pressão da raiz causada pelo consumo de $\mathrm{O}_{2}$ nas condições presumidas do método de manometria de volume constante esta representada pela Equação 3, que relaciona a pressão parcial de $\mathrm{O}_{2}\left(\mathrm{dO}_{2}\right)$ e a pressão interna do órgão, medida no manômetro de coluna d'água $(\mathrm{dH})$ :

$$
\mathrm{dO}_{2} / \mathrm{dH}=\left(\alpha_{\mathrm{CO} 2}+\mathrm{V}_{\mathrm{g}} / \mathrm{V}_{\mathrm{L}} \cdot \mathrm{RT}\right) /\left(\alpha_{\mathrm{O} 2}-\alpha_{\mathrm{CO} 2}\right)
$$

$\mathrm{Na}$ Equação 3: $\alpha_{\mathrm{CO} 2}$ e $\alpha_{\mathrm{O} 2}$ são as solubilidades do $\mathrm{O}_{2} \mathrm{e}$ $\mathrm{CO}_{2}$ em água na pressão e temperatura do ensaio $\left(\mathrm{mol}^{2}\right.$ litro $\left.{ }^{-1}\right) ; \mathrm{V}_{\mathrm{g}}$ é o volume gasoso do órgão em litros; $\mathrm{V}_{\mathrm{L}}$ é o volume de líquido do órgão em litros; $R$ é a constante dos gases $\left(8,3143 \mathrm{~J} \mathrm{~K}^{-1} \mathrm{~mol}^{-1}\right)$ e T é a temperatura em Kelvin.

A Equação 3 não pode ser empregada com exatidão durante um processo de lavagem porque os termos $\mathrm{V}_{\mathrm{g}}$ e $\mathrm{V}_{\mathrm{L}}$ variam, ao contrário do que ocorre durante um ensaio típico de manometria de volume constante. Apesar destes desvios, houve um decréscimo quase linear de pressão no tempo o que sugere que a taxa de consumo de $\mathrm{O}_{2}$ tenha se mantido praticamente constante.

\section{Obstrução das trocas gasosas}

Na Figura 4 observou-se que houve redução na taxa de difusão de $\mathrm{O}_{2}$ (TDO) que é proporcional a redução da concentração de $\mathrm{O}_{2}$ durante o processo de imersão, o que é coerente com os dados de manometria considerados no item anterior. Durante o ensaio de lavagem fato que mereceu atenção foi o bloqueio

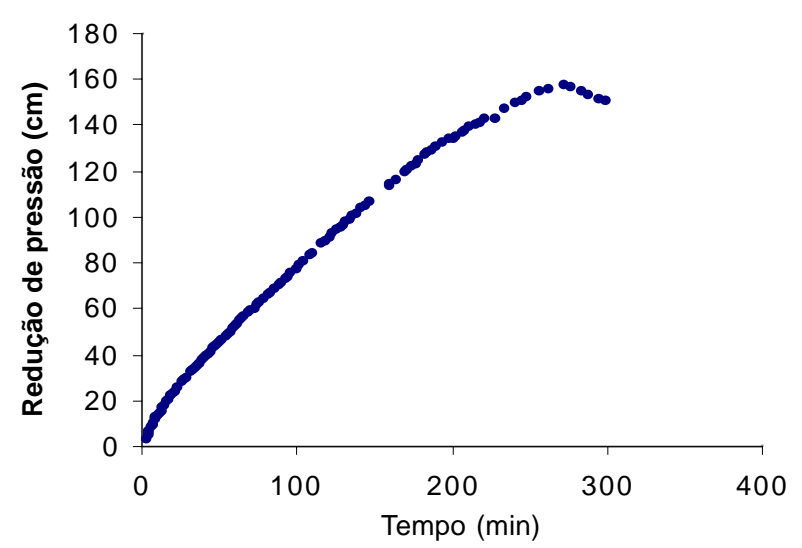

Figura 3 - Curva de redução de pressão da atmosfera interna de uma raiz de batata-doce em um ensaio de manometria de volume constante com procedimento de Nery \& Calbo (1994). 


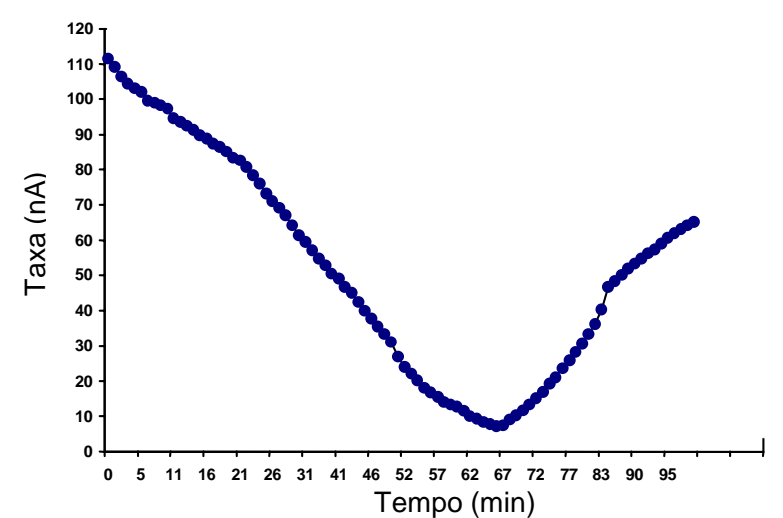

Figura 4 - Taxa de difusão de $\mathrm{O}_{2}$, de segmentos radiculares de ba tata-doce $c v$. Brazlândia Roxa após serem imersos em água. A imersão durou 60 minutos e após isto os segmentos ficaram expostos ao ar.

temporário das trocas gasosas após a retirada do órgão da água. Esse bloqueio foi provocado pela fina camada de água que envolveu a superfície do órgão também foi perceptível nas curvas de TDO. Imagina-se que após a desobstrução de algumas aberturas dermais haja o restabelecendo da difusão de gases entre a atmosfera interna do órgão e a atmosfera circundante. O restabelecimento desse contato permitiu o gradual retorno da pressão interna do órgão (Figuras 2 e 3 ) ao equilíbrio com a pressão barométrica local, bem como o retorno da concentração de $\mathrm{O}_{2}$ na atmosfera interna aos valores iniciais (Figura 4)

\section{Variação do Volume Gasoso e do Volume Intercelular}

No ensaio 3 a variação do volume gasoso intercelular $\left(\Delta \mathrm{V}_{\mathrm{g}}\right)$ estimada de acordo com os valores de massa e volume antes e depois das raízes submetidas a imersão total em água (sem suspiro) e a imersão parcial (com suspiro) por uma hora. Nas raízes que ficaram completamente imersas houve uma redução do volume gasoso de $-0,078 \pm 0,089 \%(\mathrm{v} / \mathrm{v})$ e nas parcialmente imersas houve um aumento do volume gasoso de 0,103 $\pm 0,096 \%(\mathrm{v} / \mathrm{v})$. $O$ volume gasoso intercelular inicial médios destas raízes foi $6,36 \%(\mathrm{v} / \mathrm{v})$. O aumento do volume inter-celular calculado de acordo com o aumento do volume do órgão (Equação 2) foi 0,33\% (v/v) nas raízes totalmente imersas e praticamente nulo nas raízes parcialmente imersas.

Estes resultados sugeriram duas implicações: 1) Ocorreu entrada de água nos $\mathrm{V}_{\mathrm{i}}$ dos segmentos radiculares da batata-doce totalmente imersas (sem suspiro) e 2) Ocorreu crescimento dos $V_{i}$ dos segmentos radiculares de batata-doce durante o processo de lavagem por imersão em água.

A idéia de que ocorreu infiltração de água foi também reforçada pelo fato de a curva de pressão versus tempo obtidas no primeiro ensaio (Figura 2) apresentar variação máxima de pressão $(\cong 1,30 \mathrm{~m})$ menor que a curva obtida por meio do ensaio de manometria constante

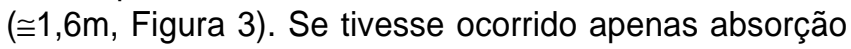
de água a redução de pressão deveria ser igual, pois seria razoável esperar que a relação $\mathrm{V}_{g} / \mathrm{V}_{\mathrm{L}}$ ficasse constante na Equação 3.

\section{Absorção e infiltração de água}

No ensaio 4 procurou-se discriminar quanta água foi absorvida e quanta água foi infiltrada em um ensaio com raízes inteiras e segmentadas. Observa-se na TABELA 1 que o aumento da massa das raízes foi maior nas raízes complemente imersas e muito maior nas raízes segmentadas. $O$ volume gasoso intercelular diminuiu mais nas raízes completamente imersas, principalmente quando segmentadas. O volume intercelular, ao contrário, aumentou mais nas raízes segmentadas. Ficou claro que a diminuição do volume gasoso foi causada pela água remanescente nos volumes intercelulares ao final do ensaio.

$\mathrm{O}$ aumento da massa dos segmentos radiculares de batata-doce durante a lavagem ocorreu por absorção e também por infiltração de água. Tomou-se como medida de absorção de água o valor do aumento da massa das raízes parcialmente imersas (TABELA 1). Os aumento adicional de massa causado pela imersão foi tomado como estimativa da infiltração através dos volumes intercelulares abertos, nas áreas cortadas. A infiltração foi o processo dominante e dependeu do gradiente de pressão (Figuras 2 , 3) gerado pelo consumo de $\mathrm{O}_{2}$ (Figura 4) e da adsorção da água pelas superfícies hidrofílicas das paredes celulares.

A absorção de água que foi presumidamente movida pelo gradiente do potencial de água entre os tecidos e a água livre ocorreu através de paredes e membranas celulares. Neste transporte somente só são carreados com a água partículas partículas menores que um limite de exclusão da ordem de alguns nanômetros atravessam as paredes celulares e eventualmente até as membranas celulares dos tecidos dermais intactos (Steudle et al., 1993). Durante a lavagem, porém, uma grande fração do aumento da massa do órgão ocorreu porque a água infiltrou-se pelos volumes intercelulares das raízes mecanicamente danificadas (TABELA 1). Na infiltração o tamanho das partículas que podem penetrar a hortaliça fica limitado pelas dimensões dos espaços intercelulares. Se a penetração de microrganismos é praticamente impossível através de tecidos dermais intactos, o mesmo não se pode afirmar sobre a infiltração de água em fluxo de massa através de volumes intercelulares de hortaliças mecânicamente danificadas

$\mathrm{Na}$ verdade, a infiltração de água pode provocar o arrastamento de impurezas para qualquer ponto do interior do órgão. Para isso basta que impurezas como bactérias possuam pouca afinidade pela superfície celular graças a físico-químicas de interação com estas superfícies. Para estas partículas altamente penetrantes o tratamentos químico posterior com agentes como o cloro ativo pode não ser completamente eficaz, porque a penetração destas substâncias fica limitada por sua permeação e por suas interações nas paredes celulares. 
TABELA 1 - Variações percentuais da massa, volume, volume intercelular, volume gasoso, volume gasoso infiltrado com água, água infiltrada através dos volumes intercelulares e da água absorvida diretamente dos volumes intercelulares em raízes de batata-doce cv. Brazlândia Roxa inteiras e cortadas transversalmente ao meio durante um período de uma hora. $O$ ensaio com raízes totalmente imersas em água e parcialmente imersas em água ocorreu a $22^{\circ} \mathrm{C}$. Nas raízes parcialmente imersas deixou-se um suspiro no tecido dermal para que a pressão da atmosfera interna se mantivesse constante. O volume intercelular total das raízes neste ensaio foi de $6,74 \pm 0,1 \%(v / v)$.

\begin{tabular}{|c|c|c|c|c|}
\hline & \multicolumn{2}{|c|}{ Raiz inteira } & \multicolumn{2}{|c|}{ Raiz cortada ao meio } \\
\hline & Imersão parcial & Imersão co mpleta & Imersão parcial & Imersão co mpleta \\
\hline & $--\cdots$ & - & - & - \\
\hline Aumento da massa & $0,173 \pm 0,037$ & $0,481 \pm 0,093$ & $0,545 \pm 0,085$ & $1,428 \pm 0,117$ \\
\hline Aumento do volume & $-0,022 \pm 0,029$ & $0,213 \pm 0,080$ & $0,386 \pm 0,089$ & $1,164 \pm 0,107$ \\
\hline Variação do volume intercelular & $-0,0014 \pm 0,0019$ & $0,014 \pm 0,005$ & $0,027 \pm 0,006$ & $0,080 \pm 0,008$ \\
\hline Variação do volume gasoso & $-0,207 \pm 0,019$ & $-0,300 \pm 0,033$ & $-0,193 \pm 0,026$ & $-0,355 \pm 0,039$ \\
\hline Água nos volumes intercelulares & $0,206 \pm 0,020$ & $0,314 \pm 0,035$ & $0,220 \pm 0,029$ & $0,435 \pm 0,042$ \\
\hline $\begin{array}{l}\text { Água infiltrada através dos } \\
\text { volumes intercelulares }\end{array}$ & $-0,000 \pm 0,040$ & $0,298 \pm 0,082$ & $0,353 \pm 0,089$ & $1,247 \pm 0,113$ \\
\hline $\begin{array}{l}\text { Água absorvida dos volumes } \\
\text { intercelulares }\end{array}$ & 0,000 & $0,209 \pm 0,028$ & $0,146 \pm 0,084$ & $0,839 \pm 0,090$ \\
\hline
\end{tabular}

Ficou evidenciado que o processo de lavagem de um órgão vegetal por imersão em água provoca alguns efeitos biofísicos e fisiológicos temporários, como a redução da pressão interna, o aumento do volume intercelular, a entrada de água dentro do tecido através dos espaços intercelulares e a obstrução das trocas gasosas do órgão. Estas observações suscitam novas dúvidas sobre como e quanto as partículas como bactérias e esporos podem penetrar as plantas durante o processo de imersão. Questões como estas deverão merecer atenção dos biologistas e poderão constituir objetos de futuros trabalhos.

\section{REFERÊNCIAS BIBLIOGRÁFICAS}

CALBO, A.G.; NERY, A.A. Methods to measure gaseous volme in plants. Revista Brasileira de Fisiologia Vegetal, v.6, p.153-162, 1994.

CALBO, A.G.; NERY, A.A. Methods for measurement of gas volume of fruits and vegetables. Journal of the American Society for Horticultural Science, v.120, p.217-221, 1995.
CALBO, A.G.; NERY, A.A.; HERRMANN, P.S.P. Intercellular deformation in compressed organs. Annals of Botany, v.76, p.365-370, 1995.

JEFFREE, C.E.; DALE, J.E.; FRY, S.C. The genesis of intercellular spaces in developing leaves of Phaseolus vulgaris L. Protoplasma, v.132, p.90-98, 1986.

KOLLÖFFEL, C.; LINSSEN, P.W.T. The formation of intercellular spaces in the cotyledons of developing and germinating pea seeds. Protoplasma, v.120, p.12-19, 1984.

NERY, A.A.; CALBO, A.G. Adaptation of constant volume manometry for the study of gas exchange by bulky organs. Journal of the American Society for Horticultural Science, v.119, p.1222-1229, 1994.

STEUDLE, E.; MURRMANN, M.; PETERSON, C.A. Transport of water and solutes across maize roots modified by puncturing the endodermis. Further evidence for the composite transport model of the root. Plant Physiology, v.103, p.335-349, 1993.

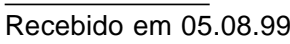

